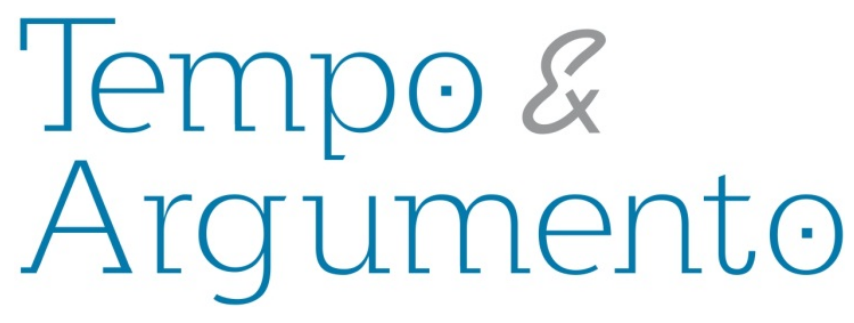

\title{
"Por primera vez en mi vida me sentí uruguayo". Ditadura, matrimonio igualitário, teoria queer e outras lutas LGBT no Uruguai. Memórias e leituras do ativista e professor Diego Sempol
}

\section{Entrevistado}

Diego Sempol é graduado pelo Instituto de Profesores Artigas (IPA, Uruguai), com especialidade em história. Fez pós-graduação em história contemporânea no Instituto Universitário do CLAEH. É doutor em Ciências Sociais pela Universidad Nacional General Sarmiento (IDES, Argentina), professor e pesquisador junto ao Instituto de Ciência Política (FCS-Udelar, Uruguai). Publicou artigos e libros sobre sexualidade, movimentos sociais e passado recente. Entre os trabalhos recentes destacam-se: "Violence and the emergence of gay and lesbian activism in Argentina, 1983-1990" que compõe o livro The Sexual History of the Global South. Sexual Politics in Africa, Asia and Latin America (Wieringa, S. Sivori; H. Zed Books London New York, 2012), De los baños a la calle. Historia del movimiento lésbico, gay trans uruguayo 1984-2013 (Debate, 2013) e De silencios y otras violencias. Políticas Públicas, regulaciones discriminatorias y diversidad sexual (Mides, 2014). Alem disso, é fundador do Colectivo Ovejas Negras e da Federación Uruguaya de la Diversidad Sexual, além de ser coordenador da Área Académica Queer Montevideo. (sempoldiego@gmail.com)

Entrevista concedida na cidade de Montevidéu

em: 14/08/2014

\section{Entrevistador}

Robson Laverdi

Doutor em História Social pela Universidade Federal Fluminense. Professor da Universidade Estadual de

Ponta Grossa. Brasil

robson_laverdi@outlook.com

\section{Transcrição}

\section{Laura Ortiz}

Doutoranda do Programa de Historia Oral. Universidad de Buenos Aires.

Bolsista CONICET.

Argentina. malauraortiz@gmail.com

\section{Para citar esta entrevista:}

SEMPOL, Diego. "Por primera vez en mi vida me sentí uruguayo". Ditadura, matrimonio igualitário, teoria queer e outras lutas LGBT no Uruguai. Memórias e leituras do ativista e professor Diego Sempol. [Entrevista realizada em 14 de agosto, 2014]. Revista Tempo e Argumento, Florianópolis, v. 7, n. 16, p. 266 - 283, set./dez. 2015. Entrevistador: Robson Laverdi. 
Tempo e Argumento - Diego, contame un poco de tu historia. Creo que la militancia, tu actividad académica, me traen acá para entrevistarte. Me parecería bueno conocer un poco sobre ti ¿quién es, Diego Sempol?

Diego Sempol - ¿Quién soy? Quién intento ser, quién soy, quién fui. Todo mezclado... Soy uruguayo, nací en 1971 y tengo 43 años. Soy un apasionado del estudio y siempre me gustó indagar. Tempranamente me enamoré de la historia, pero como mis preguntas académicas - estaban mucho más allá de lo histórico, resolví romper con los límites de esta disciplina y hacer mi doctorado en Ciencias Sociales. Además, en el camino también me hice periodista, porque me empezaron a interesar los problemas del presente, y entonces hacer entrevistas y notas me permitió conocer la realidad de primera mano. Ese cambio también estuvo ligado con lo que fue el desarrollo de mi actividad como activista. Milité durante mi adolescencia a nivel estudiantil. En los últimos años de la dictadura estaba en el liceo y formé parte de una agrupación que se llamaba Artiguismo Democrático Revolucionario, una organización estudiantil que fue opositora al régimen dictatorial y que buscaba que el sistema educativo respondiera verdaderamente a las necesidades de los estudiantes. Experiencia gracias a la que entré en contacto con el Frente Amplio. En este país, si militas a nivel social es muy difícil que no termines conectándote con los partidos políticos, porque es un sistema partidocéntrico. Empecé entonces a militar en un grupo de izquierda que se llamaba Izquierda Democrática Independiente (IDI) y después me fui con el Partido por la Victoria del Pueblo (PVP), sector en el cual milito hasta el presente. Tuve altos y bajos allí ya que experimenté situaciones de discriminación por mi orientación sexual, lo que generó que me distanciara durante los años noventa, momento en donde me conecté con las organizaciones de la diversidad sexual. Participé en algunas a fines de los años noventa y principios del siglo XXI, hasta que me fui porque sentía que no era un espacio que me interesara como estaba pensado. Pero tenía ganas de seguir trabajando en esa área. Antes también había trabajado en el área del uso de sustancias psicoactivas. Había intentado crear una asociación de usuarios de drogas para promover la metodología de reducción de riesgos y daños, pero no había cuajado, no era el momento. Entonces me quedé trabajando en el área de diversidad sexual y ahí con otros amigos fundamos en el 
2004, el colectivo Ovejas Negras. Básicamente lo que buscamos fue desarrollar una perspectiva diferente a la que se venía aplicando en los noventa. Hasta ese momento el movimiento llevaba adelante lo que yo identifico como una agenda liberal. Las organizaciones solo se expedían sobre cuestiones gays, lesbianas y trans; no intervenían ni se pronunciaban sobre ningún otro problema social. La idea de Ovejas Negras fue exactamente la opuesta: entender los problemas de discriminación por orientación sexual insertos en un marco social más complejo. Aplicamos y empezamos a construir la categoría de interseccionalidad antes que la conociéramos teóricamente. Nos dimos cuenta que no solo nos discriminaban por ser gay, lesbianas y trans, sino también por ser gays afrodescendientes, lesbianas pobres, o trans con bajo nivel educativo, lo que exigía trabajar todo el campo social, vincularnos en otras luchas sociales y promover la transversalización de nuestra agenda en otros movimientos sociales.

La otra característica de Ovejas Negras fue que decidimos desde el inicio ser una organización horizontal. Las organizaciones de los noventa habían desarrollado formas de caudillismo informal, algo que no sólo no acumulaban a nivel político sino que no promovía la participación. Era una reproducción acrítica del patriarcado. Entonces si queríamos realmente construir nuevas formas de vínculo era imprescindible pensar la dinámica desde otro lugar. Este cambio en el enfoque y la forma de trabajo impactó en forma significativa en la construcción de un movimiento social. Un ejemplo de esto fue el cambio en la participación en las marchas. En Uruguay las marchas del Orgullo LGTTB empezaron en 1993 pero la verdad es que todos los años participaban muy pocas personas. Apenas 300 valientes se animaban a superar el miedo y la persecución y ocupar el espacio público. Nosotros con esta nueva perspectiva, en el 2005, decidimos pasar a llamarla "marchas de la Diversidad” y convocar a ese espacio al feminismo, a las organizaciones afrodescendientes, al movimiento estudiantil, al movimiento canábico y a la central obrera (PIT-CNT). La nueva forma de trabajo cuajó y se comenzó a generar una movilización significativa. Por ejemplo el año pasado asistieron a la Marcha de la Diversidad 30.000 personas. Hoy esta marcha constituye uno de los momentos de mayor movilización social en el calendario de Montevideo. A su vez, este diálogo con los otros movimientos sociales generó que se transversalizara nuestra agenda: aparecieron 
comisiones de género y diversidad sexual dentro del movimiento estudiantil, dentro del PIT-CNT y varias organizaciones afrodescendientes comenzaron a trabajar este tema. Con los años se formó un bloque político informal que fue el motor de todas las conquistas legales que hemos logrado en Uruguay en los últimos años. Mi organización trabajó por matrimonio igualitario, por la despenalización del aborto y por la regulación de la marihuana, no liderando el proceso en todos estos temas, pero eso es lo interesante, acompañar y liderar según la agenda y la estrategia más conveniente. Porque considerábamos que eran tres problemas que estaban íntimamente relacionados, que tenían que ver con las formas de regulación estatales y sociales sobre el cuerpo y con las libertades.

A su vez, mientras me iba involucrando cada vez más en el activismo decido volver al trabajo académico. Abandono el periodismo y comencé mis estudios en un programa de doctorado en Argentina. Mi tesis de doctorado fue sobre la historia del movimiento de la diversidad sexual en Argentina y Uruguay durante las transiciones a la democracia en ambos países, lo que generó una sinergia súper-interesante. Pude trabajar y reflexionar teóricamente y al mismo tiempo emprender acciones en el presente. Ese diálogo continuo fue muy interesante, me ayudó a criticar la teoría sobre movimientos sociales y a entender la relación que estos tienen con los partidos. Y me promovió todo una reflexibilidad sobre la forma en que se investiga a nivel histórico en mi país.

Tempo e Argumento - Esta experiencia en el activismo no sólo te llevó al campo académico sino que también me parece que te permitió resignificarlo. Tal vez podrías hablarnos un poco de cómo movilizaste esos elementos de la experiencia en contacto, en conflicto o en reelaboración, dentro de la reflexión académica. En particular sobre el movimiento de lesbianas, gays y trans.

Diego Sempol - Tomé nota de la violencia que muchas veces se ejerce sobre los movimientos sociales desde el campo académico. Al trabajar en los dos campos al mismo tiempo me di cuenta cómo a veces el académico trata de hacer un paper, es totalmente invasivo y no mantiene las pautas éticas mínimas para un trabajo de 
investigación. Y después desde un lugar de sapiencia parece querer indicarle al movimiento social qué es lo que tiene que hacer y qué es lo que hizo mal. También noté como muchas veces los académicos tienen que justificar su investigación y para hacerlo llegan a situaciones un poco absurdas. Me explico: en otras partes del mundo es frecuente que la academia sea bastante posidentitaria y el movimiento muy identitario. En Uruguay afortunadamente el movimiento de la diversidad sexual es bastante posidentitario. Entonces encontraba académicos, que de repente como no tenían espacio para enunciación académica desde la perspectiva teórica en voga, retomaban tesis identitarias para poder justificar su trabajo. Me di cuenta de lo mecánico y empobrecedor que puede llegar a ser la idea de que para ser un buen académico y lograr visibilidad dentro del campo hay que ocupar un espacio crítico a como dé lugar, aunque las críticas en vez de contribuir al proceso en curso lo perjudican y desnortean. También me pareció interesante cómo en muchos sentidos la academia está ligada a intereses corporativos y cómo trabaja para el poder. La falta de reconocimiento en nuestra producción académica sobre la significación de los movimientos sociales y la complejización de su relación con los partidos políticos, es parte de toda una visión que siempre está abonando la idea de que la agencia está en los partidos políticos y no en los movimientos sociales. Cuando en realidad estaba experimentando como activista que el partido político no tenía en este caso ningún protagonismo en los cambios que se estaban logrando, el protagonismo lo tenía el movimiento social y el partido político de alguna forma fue el que capturó una agenda porque había capacidad de movilización, incidencia en la política informal y debate público significativo. Empecé a ver una cantidad de puntos ciegos en la forma tradicional en la que se pensaba este tema en Uruguay. Y por otro lado también me reveló la dificultad que tiene la academia uruguaya para pensar problemas actuales, salvo que sean temas fuertemente institucionalizados o ya legitimados en el campo. Trabajar la politización de la sexualidad para la ciencia política o la historia era un tema menor, irrelevante. Límites que tienen que ver con las propias prácticas endogámicas del campo pero además con ciertas visiones homofóbicas internalizadas que no osan a decir su nombre pero que son decisivas al momento de construir las prioridades de la agenda. O sea que este diálogo me permitió 
pensar el campo académico, verlo en su relación con el campo activista y además pensar cuestiones teóricas.

Tempo e Argumento - En tu trayectoria contás que tu pasaje del periodismo a la academia fue un cambio importante. ¿Cómo percibís hoy, dentro de la academia, la cuestión del periodismo en relación a la diversidad sexual?

Diego Sempol - Hoy es un escenario bien distinto. El semanario Brecha, en el que trabajaba fue la primera publicación en este país que efectivamente abordó el tema en forma seria, respetuosa y con profundidad. Después cuando esta agenda estalló socialmente, y ya era inevitable, empezó a haber una pluralidad de acercamientos periodísticos. En general medios como La Diaria, programas radiales como No toque nada, o Canal 10 tienen buenas coberturas que muestran la heterogeneidad de opiniones pero interpelan en forma contundente las visiones homofóbicas. Pero después las notas del matutino El País, ligado al Partido Nacional, siguen siendo muy discriminatorias. Existe con ellos aún una pugna ideológica, por ejemplo a las mujeres trans nunca le reconocen el femenino en sus notas. Usan los nombres legales masculinos en vez del nombre elegido, lo que refuerza los estereotipos que ambientan los crímenes de odio transfóbico. O por ejemplo cuando fue el debate sobre matrimonio, acá el proyecto se denominó "matrimonio igualitario", pero ellos insistín en llamarlo "matrimonio homosexual", lo que inivisibilizaba varios aspectos que incluía el proyecto, que iba mucho más allá de garantizar la unión entre personas del mismo género.

Tempo e Argumento - Hablaste sobre la importancia de la organización Ovejas Negras. Contame un poco cómo fue tu trayectoria en ella.

Diego Sempol - Fue todo un desafío. Fue la forma mediante la que logré dignificar mi orientación sexual. Antes de participar en Ovejas ya había negociado públicamente mi sexualidad, pero no lograba sentirme cómodo del todo, ahora lo puedo vivir de una forma relajada. Fue y es una experiencia afectiva fuertísima, conocés gente con la que 
compartís momentos de encuentro, de mucha exigencia, de debate político, de participación, y de construcción colectiva que te generan vínculos de confianza o de mucha bronca. Además aprendí sobre lo colectivo desde un lugar nuevo, haciendo política con el cuerpo y tu intimidad, luchando por tu derecho a existir. A su vez, como era una organización horizontal había que buscar el consenso, aprender a negociar y a dialogar. Esto me ayudó un montón a integrar perspectivas nuevas y dejar de lado ideas previas, aprendí a luchar por cuestiones que a veces no tenían nada que ver con lo que yo quería, pero que de alguna forma eran más acertadas.

Tempo e Argumento - ¿Cuáles serían esas ideas previas? ¿Cuáles serían los dilemas que te generaron esos desplazamientos? Ese movimiento a nivel de reflexión me parece importante.

Diego Sempol - Por ejemplo en mi caso me oponía a la lucha por el matrimonio igualitario por todo lo que esta institución implica. Creo que el discurso de los derechos es tramposo, te reconocen cosas, pero al mismo tiempo te congelan y normalizan. Pero durante el debate en la organización me fui dando cuenta que para muchos era una necesidad real y que tenía una utilidad política importante, lograr la igualdad jurídica iba a permitir abrir toda una serie nueva de agendas, como la educativa. También para la sociedad uruguaya el tema era relevante ya que había sectores que se oponían a la reforma y lo vivían como el último bastión del privilegio heterosexual. Por último, era una forma de atraer más gente al movimiento para que comenzara su proceso de politización. El discutir todo eso me llevó progresivamente a entender, y fui finalmente uno de los que más militó porque se aprobara el matrimonio igualitario. Otro ejemplo puede ser cómo a veces grupalmente se decide algo que es claramente un error, pero grupalmente se necesita ese paso en falso. Porque eso es un proceso de aprendizaje colectivo y lo peor que uno puede hacer es imponerse para que no suceda, o después que sucedió decir "yo te dije”. La clave es seguir construyendo colectivamente y estar también en ese proceso de aprendizaje todos juntos. 
Tempo e Argumento - En eso que planteas parece haber una autoridad construida durante el propio proceso. ¿Cómo percibís la actuación de Ovejas Negras y la tuya en el proceso que condujo hasta la aprobación de la normativa que está vigente hoy en Uruguay?

Diego Sempol - El trabajo de mi organización fue decisivo, ya que logramos construir un marco interpretativo que impactó socialmente y que hoy por hoy es el marco de casi todas las organizaciones sociales que trabajan la agenda de derechos. A tal punto fue exitoso que nuestros oponentes también lo utilizan: por ejemplo cuando fue el debate sobre matrimonio igualitario surgieron grupos de derecha que se apropiaron de nuestro marco interpretativo que juntaba todas las desigualdades, y lo usaban para nuclear a todos los que se oponían al matrimonio igualitario, aborto y regulación de la marihuana. Este marco también impactó en el movimiento a nivel nacional, la Federación Uruguaya de la Diversidad Sexual lo llevó a todas partes del país. Creo que esto fue una conquista política muy importante, que generó una gran capacidad de movilización y la construcción de un bloque político social potente.

Otro aspecto decisivo fue que Ovejas supo cuando confrontar y quemar las naves, y cuando aplaudir y reconocer. Tuvo una lectura muy política respecto a los aliados estratégicos y adversarios. Cuando se veía que no había posibilidades de avanzar más, la confrontación se desencadenaba más allá del sector político que fuera. Creo que esa flexibilidad política nos permitió realmente avanzar en un diálogo maduro con el sistema político.

Tempo e Argumento - Esa flexibilidad de la que hablás ¿cómo se tradujo en estrategias? ¿Las reflexiones producidas dentro del movimiento sobre la realidad como encarnaron en sus prácticas políticas?

Diego Sempol - En algunos casos nos dimos cuenta de que había muy poco margen, entonces desarrollamos estrategias expresivas heteronormativas para de alguna forma poder ganar legitimidad donde casi no la teníamos. Mientras que en otros espacios desarrollamos estrategias expresivas mucho más disruptivas. Me explico, por ejemplo 
cuando se empezó a instalar el tema trans había una gran resistencia, una transfobia totalmente naturalizada. Entonces la trans que fue a los medios a llevar adelante el debate político fue una que cumplía a cabalidad con los ideales regulatorios de una mujer biológica. Esto nos permitió ganar la opinión pública de centro y más conservadora que entendió que era una contradicción que esa persona tuviera un documento con un nombre masculino. Pero una vez que se logró conquistar la ley de Identidad de Género, la organización empezó a promover a trans con perfiles mucho más heterogéneos. Porque ya lograda la conquista jurídica y modificada la opinión pública era momento para combatir la ligazón entre identidad de género y anatomía. Para ser trans no tenés porque cumplir con todos los requisitos instituidos socialmente para ser hombre o mujer. Podés ser una trans femenina y tener barba, podés ser trans y te falta un diente, podés ser trans y ser obesa. Entonces por ejemplo ahí el liderazgo a nivel mediático dentro de la organización lo empezó a ocupar la Doctora Michelle Suárez Bértora, que es la primera trans abogada de nuestro país. Una universitaria brillante, pero que es una persona sumamente obesa, que no cumple para nada con los requisitos sociales que se le exigen a una trans femenina para ser aceptada. En el terreno de las lesbianas, los gays, hicimos lo mismo. Jugamos por ejemplo con las identidades para evitar la esencialización. Entonces había una convocatoria para trabajar sobre problemas de lesbianas, y por la organización iba un gay. La idea era problematizar el presupuesto de que solo las lesbianas pueden hablar de lesbianismo y que en realidad se puede construir una agenda política que más allá de la identidad personal que uno tenga, puedo sostener y llevar adelante. Como era de esperar estas estrategias generaba debates, dislocaciones, acusaciones. Pero fue realmente muy pensado para instalar, dentro de las posibilidades políticas que había, estas ideas que teníamos.

Tempo e Argumento - Me gustaría que hables sobre lo que implicó la victoria del matrimonio igualitario libremente, desde tu memoria viva, experimentada. ¿Es posible?

Diego Sempol - Sí. Fue un momento muy emotivo. Estaba en el Parlamento con mi compañero cuando se aprobó, me puse a llorar horrible. Pero sobre todo porque sentí 
por primera vez en mi vida que en este país tenía un lugar. Sentí eso. ¿No? Le dije a Aldo, “Mi amor, por fin tenemos un lugar en el mundo". Por primera vez en mi vida me sentí uruguayo, me pude reconciliar con este país en donde tanta violencia tuve que tramitar para poder llegar hasta donde hoy estoy. Me dio mucha fuerza y tranquilidad. Después de los años noventa, donde lo colectivo se había caído a pedazos y todo parecía imposible, haber logrado esta victoria me confirmó que luchando con otros, construyendo con otros, pensando con otros se puede avanzar para mejorar la calidad de la vida de todos. No sé si me voy a casar, honestamente no lo sé, pero el hecho de que seamos igualitos jurídicamente, me da un respiro en mi lucha cotidiana. Me da otros márgenes, me da otras posibilidades ... Como que ahí me cerró todo: de no estar a favor del matrimonio, al final cuando se aprobó entendí lo que significaba. Por eso cuando a veces escucho las críticas de algunos académicos uruguayos que hacen una lectura descontextualizada de la teoría queer y afirman que el matrimonio igualitario es una trampa, me hacen acordar primero a lo que pensaba cinco años atrás y después me confirman la superficialidad del análisis, que desconoce todo el proceso político de construcción y el impacto social que tuvo esta conquista jurídica. Entonces nuevamente veo esto que te planteaba hoy, la gente lee teoría, la importa acríticamente y reflexiona en forma colonizada según los viveros teóricos de turno. Es claro que no se está entendiendo el proceso en su dimensión, no se está viendo lo que impactó a nivel social. Este año he tenido más casamientos que en toda mi vida...

\section{Tempo e Argumento - ¿Muchos?}

Diego Sempol - Muchos. Por ejemplo fui a un casamiento de una pareja de lesbianas del interior del país, que antes de casarse resolvieron decirle a todo el pueblo que se amaban y que iban a volverse esposas. El pueblo vivió una especie de catarsis, una mini revolución cotidiana que fue interesantísima. Es claro que la conquista jurídica implicó un cambio significativo. Lo que no quiere decir tener una mirada complaciente, falta un montón. Pero me parece un punto de partida importantísimo. 
Tempo e Argumento - En tu relato está muy presente una discusión sobre cómo las categorías de pensamiento, de reflexión sociológica, histórica o psicoanalítica, modelan la percepción sobre lo que sería un movimiento social, una manera de pensar la sexualidad humana y su relación con la política. Hablaste sobre la teoría queer, sobre la cuestión trans y sobre la identidad lésbico-gay. ¿Cómo esta teoría se revisa o se recoloca a partir de tu experiencia concreta?

Diego Sempol - En mi experiencia personal cuando llegué a la categoría o a la identidad gay fue un acto de liberación. En los ochenta decir "gay" y no "puto" me significó mucho a nivel subjetivo. Pero después la promesa de liberación finalmente no se cumplió, la palabra gay pasó a ser un enorme problema y una fuerte restricción. Cuando empecé a politizar mi identidad sexual viví una intensa reflexión sobre lo opresivas que son las categorías y lo útil que son a su vez políticamente. Me parece que este aspecto es lo que aporta en forma significativa la reflexión queer. Hay una tensión en la que estamos atrapados: no puedo convocar a la gente sin apelar a ciertas cuestiones identitarias. Pero al mismo tiempo si esencializo mucho esas cuestiones identitarias, estoy traicionando lo que quiero generar. En esa tensión es en la que nos movimos durante todo este tiempo. Por eso dejamos de hablar de LGTTB y empezamos a hablar de diversidad sexual, para evitar esencializar las categorías. Por eso cuando había una reunión sobre lesbianas iba un gay a hablar, para problematizar todos estos usos de la identidad.

Para mí es necesario reconocer dos cosas en este terreno: por un lado que es posible construir una agenda común de lucha, ya que todas las particularidades tienen puntos de conexión importantes que me permiten en mi caso trascender la "agenda gay" e involucrarme en una lucha que también es útil para lesbianas y trans. Y por otro, debido al momento histórico en que vivimos es importante reconocer que aún en la actualidad estas particularidades continúan generando formas específicas de desigualdad que no deben ser invisibilizadas. Esto quiere decir que todos podemos militar en función de una particularidad que no es la mía, no para sustituir la voz del otro, sino para avanzar todos por igual. Porque no todos tenemos los mismos recursos simbólicos, ni materiales, ni el mismo entrenamiento en el terreno de la política. Esta apuesta colaborativa funciona 
muy bien cuando se sabe gestionar y cuando la categoría diversidad no pasa a ser un eufemismo que invisibiliza las desigualdades históricamente contingentes que vivimos y las relaciones de poder que también existen entre nosotros.

Tempo e Argumento - Diego, durante nuestra conversación, cuando te pregunté sobre tu trayectoria, una trayectoria múltiple, hablaste de un pasado, de un presente y de un futuro que se ubican en la narrativa de hoy. Vos realizaste una investigación muy importante que pude leer, sobre el terrorismo de Estado. Primero quisiera que hablaras un poco sobre tu investigación, lo que descubriste y luego sobre como esa investigación apareció en tu militancia.

Diego Sempol - Mi campo de investigación siempre fue el pasado reciente, y vengo trabajando hace años la violencia estatal, la memoria y el movimiento de Derechos Humanos. En la medida que la militancia me fue llevando al terreno de la diversidad sexual, empecé a reflexionar estos temas en clave de género y de sexualidad. Y ahí, básicamente tengo dos publicaciones diferentes. Una que es un libro que publiqué el año pasado, en donde historizo el movimiento LGBT uruguayo desde su creación'1, en 1984, el último año de la Dictadura, hasta el presente. La teoría de proceso político se centra en la estructura de oportunidad política para explicar el surgimiento de los movimientos sociales. Sin embargo, en el análisis de la historia del movimiento uruguayo encontré que las primeras organizaciones no contaron con una oportunidad política para iniciar su acción. En realidad fue la violencia estatal durante la dictadura y los primeros años de democracia la que desencadenó su aparición, y al tirar de esa línea de análisis logré sacar de la invisibilidad la violencia estatal sobre las personas no heteroconformes durante el autoritarismo, tema que aborde en un artículo recientemente publicado. ${ }^{2}$ Hice varias entrevistas a homosexuales y travestis mayores de 50 años y en todas lo que aparecía una y otra vez, era una experiencia traumática con

\footnotetext{
${ }^{1}$ De los baños a la calle. Historia del movimiento lésbico, gay trans uruguayo 1984-2013. Debate, Montevideo, 2013.

2 Sempol, D. Graña, F (2012) "Salvar la patria y a la familia. Dictadura, disidencia sexual y silencio" en Las Laurencias. Violencia sexual y de género en el terrorismo de Estado uruguayo. González, S. Risso, M (comp.) Trilce. Montevideo. pp. 85-104
} 
el Estado: la policía, las detenciones, las golpizas, las torturas, los secuestros, los chantajes. No era solo la sociedad la que discriminaba sino también el Estado. Observé la forma en que esta violencia había marcado la biografía de mis entrevistados, como los había promovido a mantenerse en el armario. En las entrevistas con personas trans aparecieron claramente dos cosas: por un lado, antes de la llegada de la dictadura en Uruguay, ellas tenían problemas con la policía, pero eran relativamente menores. Sin embargo, a partir del golpe de estado en 1973 aumentó el tiempo promedio de detención, antes era de un día o dos, durante el régimen cívico militar quince días, un mes, un mes y medio. Y también cambiaron las condiciones de detención. Antes de la dictadura no se las torturaba, durante la dictadura se las torturó en forma continua. Me impacto el silencio social que existía sobre este tema. En Uruguay se había tematizado mucho la violación de los derechos humanos durante la dictadura por motivos políticos pero nunca por cuestiones referidas a la sexualidad o a la identidad de género. Además de una violencia por motivos políticos hubo una violencia que denomino "autoritarismo moral", que promovió un modelo de familia heteropatriarcal y persiguió a los que identificaba como una amenaza a ese proyecto. Por ejemplo en 1976 el jefe de la Policía de Montevideo, a raíz del homicidio a un homosexual, detiene a más de trescientos gays los que reciben todo tipo de malos tratos durante su detención. Este tipo de razzias subsisten hasta entrados los ochenta. La policía muchas veces los sometía a la llamada "prueba del talco", que supuestamente era una prueba forense con la cual se trataba de asustar al detenido, en donde se le pedía que se sentara desnudo sobre talco, lo que supuestamente permitía constatar si tenía prácticas eróticas con su ano. Muchos detenidos temiendo la confirmación confesaban antes que eran homosexuales y a partir de eso se les impugnaban delitos, se los chantajeaba, se los sometía a todo tipo de violencia psicológica y presiones. Una cosa muy interesante es que encontré que esa violencia estatal persistió más allá de la dictadura. Si bien la democracia se instaló en Uruguay en 1985 para muchas personas la dictadura continuó por muchos años más. Comprendí entonces que existían temporalidades diferentes en la transición y que no en todo el mundo llegó la democracia al mismo tiempo. La población trans recién acarició la democracia a principios del siglo XXI cuando la policía dejó de perseguirlas, mientras que 
para los gays y lesbianas este tránsito se produjo a principios de los noventa, momento en que cesaron definitivamente las razzias policiales en sus centros de reunión nocturnos.

Tempo e Argumento - Estas cuestiones se refieren a mi propia investigación sobre homosexualidad en Brasil; una de las cuestiones que me parece transversal, es la cuestión de la sexualidad, la diversidad sexual y de las relaciones sociales. ¿Existen hoy cambios en este eje?

Diego Sempol - Noto cambios muy importantes, incluso han aparecido nuevas formas de sociabilidad. Para los hombres que desean a otros hombres y que son más jóvenes que yo, la variable edad es mucho más importante que para mi generación cuando estaba viviendo la franja de los veinte. Cuando empecé a vivir una sociabilidad gay interactuaba con personas de diferentes edades porque lo que nos unía era que todos éramos homosexuales. Ahora, con la progresiva disminución de la discriminación la variable de edad se vuelve un diacrítico crítico, en el sentido que es más importante tener el mismo rango etario que compartir una misma orientación sexual. Lo veo incluso en Ovejas en donde muchas veces con las personas que tienen veinte años tengo muy poco intercambio.

Tempo e Argumento - ¿Crees que la corporalidad postulada por los valores predominantes juega un papel en este tema?

Diego Sempol - Creo que los imaginarios sobre el cuerpo lo vivimos todos, es un problema transgeneracional. Hay una cultura juvenil muy ligada a la cultura gay mainstream que implica estándares muy opresivos: si no sos "lindo", joven, y lucís un cuerpo escultural no hay posibilidades de tener una vida digna y feliz. Creo que lo que falta todavía es un trabajo muy fuerte hacia adentro de los grupos de gays y lesbianas y trans, para modificar la propia homo-lesbo transfobia interna, para desarticular formas de resistencia que fueron efectivos en la etapa previa a todos estos cambios, pero que en el presente obturan la posibilidad de avanzar a nivel cultural. Y después falta también 
transformar la cultura de la gente en general. Se ha avanzado mucho pero estamos en un régimen de transición, donde lo viejo y lo nuevo se dan en la mano. Voy a mi facultad y es como una burbuja: ves a dos chicas besándose y eso no llama la atención a nadie. Pero si vas a algunos barrios periféricos de Montevideo, el mismo hecho puede desencadenar formas de violencia física. Y esa son las diferentes temporalidades en las que estamos metidos en este régimen de transición.

Tempo e Argumento -¿Cómo percibís algunos de los desafíos que se colocan en ese plano?

Diego Sempol - Para mí lo central ahora es trabajar la educación. En Uruguay todo el mundo pasa el sistema educativo y este tiene una capacidad de legitimación y naturalización muy importante. Hay que repensar todo el sistema educativo en función de la nueva realidad jurídica. Por ejemplo los baños no deberían estar más generizados, en nuestras casas no hay baños para mujer y hombre, sino que todos/as usamos el mismo y eso no genera ningún tipo de conflicto. Es necesario problematizar el implícito heteronormativo que tiene el sistema educativo, para pasar a reconocer la diversidad social existente. Hay diferentes modelos de familia, hay diferentes posibilidades de explorar la sexualidad; y todas son legítimas y todas son válidas. Entonces el sistema educativo tiene que dar cuenta de esa heterogeneidad social en sus formularios, en sus prácticas educativas, en sus discursos institucionales, en sus cartelerías, en sus fiestas y reglamentación interna. O sea, hacer una modificación de todos estos niveles institucionales que de alguna forma refuerzan siempre un discurso heteronormativo que excluye del espacio de aula la sexualidad y ni que hablar de la sexualidad no heteronormativa.

El otro tema clave es seguir avanzando más en la inclusión laboral de la población trans y garantizarles su acceso al sistema educativo. Cuanto mejor sea su nivel educativo mayores serán sus niveles de empleabilidad. Además es necesario trabajar el sistema de salud para volverlo verdaderamente universal. La población trans no tiene acceso a hormonas en forma gratuita, ni a actualmente a operaciones de reasignación de sexo. 
Las transformaciones corporales son vistas por el sistema médico como transformaciones estéticas, cuando en realidad están vinculadas a la identidad. Las lesbianas también tienen importantes problemas al momento de enfrentar a un ginecólogo y los gays barreras significativas para acceder a tratamientos de calidad para cuidar la salud recto anal.

Tempo e Argumento - ¿Cómo se están discutiendo estos problemas hoy en Uruguay?

Diego Sempol - Ovejas en el terreno educativo ha hecho alianza con algunos programas de educación estatal que ya existían, con los que desarrollamos cursos para docentes sobre diversidad sexual y género. Ahora estamos por publicar en setiembre una guía para docentes referida a cuestiones de diversidad sexual y hacemos talleres en centros educativos. En octubre vamos a hacer la primera jornada académica sobre educación y violencias, para empezar a construir un campo de reflexión que nos permita llegar a construir protocolos para abordar los problemas de violencia homo-lesbo-transfóbica, étnico-racial, por clase, y por género dentro del sistema educativo.

Tempo e Argumento - Diego, ya terminando, me gustaría saber si hay algo que no te pregunté pero que considerás que sería importante para dar cuenta de tu trayectoria personal.

Diego Sempol - Algo que me pasó toda mi vida es que, cada vez que estuve en un lugar, nunca se me reconoció ese lugar. Me explico. Cuando trabajaba como periodista, me decían que era académico. Cuando empecé a trabajar como académico, me decían que era periodista. Cuando empecé a ser activista, me decían que era un político. Cuando iba al partido político, me decían que era un activista. Siento que en mi vida he tenido que luchar muchas veces con las categorías. Siempre el otro insiste en estabilizarte, en no reconocerte un lugar que esta fuera de lo esperable. Jugar con los intersticios, con los caminos en donde las cosas se unen, es el camino más rico para poder pensar, para poder conectar subjetividad con reflexión académica, vida cotidiana con espacios laborales. Sin embargo, buena parte del mundo insiste en tratar de fragmentarlo todo, e 
insiste siempre en tratar de impedir que vos hagas ese diálogo y no veas la riqueza de los puentes. Las conexiones que existen y que operan, invisibilizan lo que opera, lo que termina por empobrecer la mirada y el recorrido de la gente.

Tempo e Argumento - Ese argumento es muy interesante, pero surge a partir de tu disposición de frecuentar esos espacios, esos lugares. Estas diferentes experimentaciones del mundo que vos contás, y que vos relacionás, tienen que ver con ese lugar que de alguna forma nosotros los homosexuales vivimos. La localización muy estricta de la clandestinidad o la semiclandestinidad, la cuestión del espacio público y del espacio privado. ¿Cómo pensás eso?

Diego Sempol - Los discursos sociales sobre la homosexualidad nos ponen estrictos límites en el terreno de la sociabilidad. No te acerques mucho a los niños, o demostrás frente a los niños que no se te nota que sos homosexual, porque la idea de "contagio" o de abuso, está todo el tiempo circulando. La desconfianza que genera que seas un docente y al mismo tiempo digas explícitamente que sos homosexual nos vuelve personas mucho más desacreditables que otras. $Y$ eso a su vez lo que genera es un autodisciplinamiento que a veces es agotador. No sólo tenés que ser bueno sino que tenés que parecerlo. Estos estrechos márgenes son muy empobrecedores, inhiben la espontaneidad y la posibilidad de avanzar. Yo he oscilado según los contextos. En escenarios de alta discriminación tiendo a volverme muy controlado sobre qué cosas despliego en ese lugar. $Y$ en otros contextos más amigables tiendo a distenderme y a explorar. Me gustaría poder vivir en un mundo en el cual realmente pudiera fluir. Porque capaz que me permitiría conectarme con cosas que ni siquiera hasta el momento pude. Creo que muchas veces el conocimiento, el crecimiento se produce con el otro y a partir del otro. Entonces a mí siempre me queda la duda de que tantas cosas nunca pude haber conocido o visto porque nunca tuve la oportunidad de ser con el otro. 
“Por primera vez en mi vida me sentí uruguayo". Ditadura, matrimonio igualitário, teoria queer e outras lutas LGBT no Uruguai. Memórias e leituras do ativista e professor Diego Sempol

Tempo e Argumento - Diego, quiero agradecerte muchísimo.

Diego Sempol - Gracias a vos. ¿Te fue útil?

Tempo e Argumento - Muchísimo.

Universidade do Estado de Santa Catarina - UDESC

Programa de Pós-Graduação em História - PPGH

Revista Tempo e Argumento

Volume 07 - Número 16 - Ano 2015

tempoeargumento@gmail.com 